\title{
Computational Tools to Rationalize and Predict the Self-Assembly Behavior of Supramolecular Gels
}

\author{
Ruben Van Lommel ${ }^{1,2, *(\mathbb{C})}$, Wim M. De Borggraeve ${ }^{1}\left(\mathbb{D}\right.$, Frank De Proft ${ }^{2}$ and Mercedes Alonso ${ }^{2, *(1)}$ \\ 1 Molecular Design and Synthesis, Department of Chemistry, KU Leuven, Celestijnenlaan 200F Leuven Chem \& \\ Tech, P.O. Box 2404, 3001 Leuven, Belgium; wim.deborggraeve@kuleuven.be \\ 2 Eenheid Algemene Chemie (ALGC), Department of Chemistry, Vrije Universiteit Brussel (VUB), Pleinlaan 2, \\ 1050 Brussels, Belgium; fdeprof@vub.be \\ * Correspondence: ruben.vanlommel@kuleuven.be (R.V.L.); mercedes.alonso.giner@vub.be (M.A.)
}

check for updates

Citation: Van Lommel, R.; De Borggraeve, W.M.; De Proft, F.; Alonso, M. Computational Tools to Rationalize and Predict the Self-Assembly Behavior of Supramolecular Gels. Gels 2021, 7, 87. https://doi.org/10.3390/gels7030087

Academic Editor: Pablo H. Di Chenna

Received: 27 May 2021

Accepted: 6 July 2021

Published: 9 July 2021

Publisher's Note: MDPI stays neutral with regard to jurisdictional claims in published maps and institutional affiliations.

Copyright: (c) 2021 by the authors. Licensee MDPI, Basel, Switzerland. This article is an open access article distributed under the terms and conditions of the Creative Commons Attribution (CC BY) license (https:// creativecommons.org/licenses/by/ $4.0 /)$.

\begin{abstract}
Supramolecular gels form a class of soft materials that has been heavily explored by the chemical community in the past 20 years. While a multitude of experimental techniques has demonstrated its usefulness when characterizing these materials, the potential value of computational techniques has received much less attention. This review aims to provide a complete overview of studies that employ computational tools to obtain a better fundamental understanding of the selfassembly behavior of supramolecular gels or to accelerate their development by means of prediction. As such, we hope to stimulate researchers to consider using computational tools when investigating these intriguing materials. In the concluding remarks, we address future challenges faced by the field and formulate our vision on how computational methods could help overcoming them.
\end{abstract}

Keywords: supramolecular gels; LMWG; computational chemistry; molecular dynamics; modeling; self-assembly

\section{Introduction}

Supramolecular gels, often referred to as molecular gels or low molecular weight gels (LMWGs), are a type of soft material that mostly consists of two constituents: a solvent, which accounts for up to $99 \%$ of the material, and a small molecule termed a gelator. Although only present in small amounts, the gelator provides the material with the typical viscoelastic gel properties, by forming a self-assembled network that spans and immobilizes the solvent [1-4]. While there is a large chemical diversity among reported gelators, most of them rely on the ability to form intermolecular noncovalent interactions in an anisotropic fashion. Hence the term supramolecular gels. In the past decade, the field of supramolecular gels has reached its adolescent years, providing researchers with ample well-established experimental techniques to characterize and investigate these materials, amongst others rheological measurements, various microscopy imaging techniques, NMR spectroscopy, UV-VIS spectroscopy, etc. [5-8]. Evidently, these experimental techniques have played a critical part in establishing our current understanding and development of supramolecular gels and will remain essential in the forthcoming years.

However, the macroscopic properties of these soft materials are governed by weak noncovalent interactions. Gaining direct insights into these interactions via wet-lab experiments is challenging. Fortunately, in the past, various computational methods and tools have proven their usefulness when investigating noncovalent interactions in supramolecular materials [9-11]. In this review, we set out to create awareness on the use of computational chemistry within the field of supramolecular gels. The first part discusses how computational methods can help to improve our understanding of supramolecular gels, often complementing the observations from experimental techniques. Next, several recent computational studies aiming to accelerate the development of supramolecular gels by a priori predictions are highlighted. In the concluding section, we look forward towards 
the opportunities and challenges that remain in the field of supramolecular gels where computational methods can be of considerable value.

\section{Rationalizing Supramolecular Gelation}

Gaining a deeper understanding of supramolecular gels is not only useful for scientific purposes, but it can also aid in their development and increase their applicability. To this end, several computational techniques have been applied to acquire knowledge about the conformational preference of gelators in a solvent environment, possible stacking modes of the nano-architectures, the noncovalent interactions in and between gelator molecules and additives, etc. Having said that, supramolecular gelation is a multiscale problem, with interactions occurring at the atom scale governing macroscale material properties [2,12]. As a result, different computational techniques with different levels of accuracy are required to gain information at different scales (Figure 1). In this section, an overview of computational methods employed to rationalize the gelation behavior is provided. While this section is organized based on the scale and level of accuracy of the computational method, we do mention that in order to obtain the most complete picture, a combination of these techniques integrated in a multiscale approach is desirable [13-15].

\section{Scale}
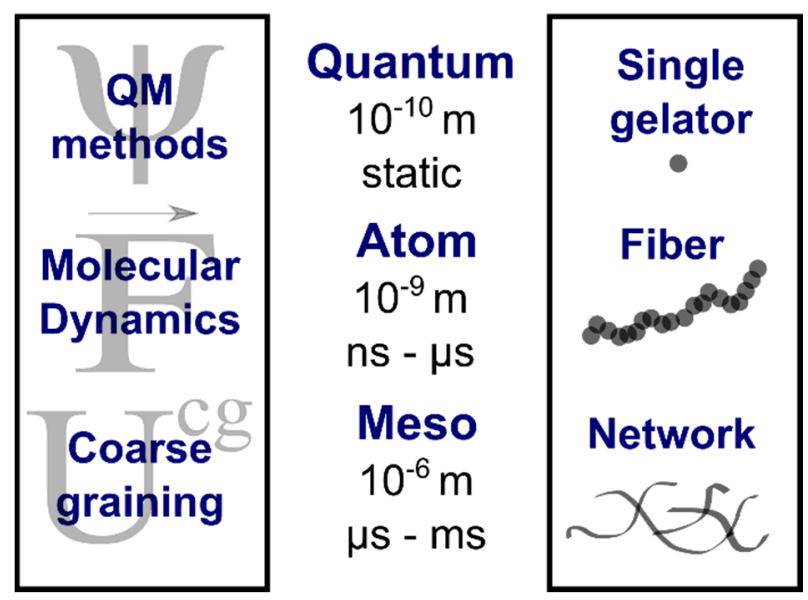

Figure 1. Computational methods with different levels of accuracy can provide information on the supramolecular gelation behavior at different length and time scales.

\subsection{Static Quantum Mechanical Calculations}

Computations performed with techniques that rely on quantum mechanics, generally yield highly accurate properties. Even within quantum mechanical methods, subdivisions of techniques can be made based on the manner in which electron correlation effects are taken into account [16]. This means, however, that they also require a significant amount of computational power. Hence, quantum mechanical calculations in the field of supramolecular gels are currently limited to static or short dynamic simulations of single gelator molecules or systems of up to approximately 500 heavy atoms. Additionally, solvent effects (if any) are included by implicit continuum models or explicitly by molecular mechanics methods (QM/MM). Among the many quantum mechanical theories available, density functional theory (DFT) has established itself as the primary quantum mechanical workhorse to investigate supramolecular systems [17-19]. The popularity of DFT can be attributed to its favorable balance between accuracy and computational cost, its flexibility (i.e., a myriad of exchange correlation functionals are developed to address different problems) and its ease of use (i.e., several user-friendly software packages exist, to set up a DFT calculations in a matter of seconds). Nevertheless, it is well known that conventional DFT functionals fail in describing long-range dispersion interactions, which are crucial to accurately model the noncovalent interactions in a supramolecular gel [20-22]. Luckily, 
numerous methods to improve the description of long-range dispersion interactions have been developed, including long-range corrected functionals [23,24], atom-pairwise additive schemes [25], or non-local dispersion corrections [26,27]. It goes without saying that, when studying supramolecular gels using DFT, attention must be paid to accurately describe long-range dispersion effects in order to obtain meaningful results.

In 2008, Urbanová and co-workers were one of the first to obtain structural information of a supramolecular gel from DFT calculations [28]. In their work, the structure of a guanine derived supramolecular hydrogel was investigated by systematically computing stable conformations of a simplified model of the gelator, ranging from dimers to tetramers. By comparing the DFT calculated VCD and IR spectra with the corresponding experimental spectra of the hydrogel, a plausible supramolecular stacking model was put forward. The proposed stacking model relied on Hoogsteen base pairing hydrogen bonds between the gelators [29]. Importantly, only a good agreement with the experimental spectra could be obtained by adding a sodium ion to the structure. The researchers rationalized that the presence of the sodium ion could stem from the $\mathrm{pH}$-triggered gelation procedure (Figure 2). Following this study, other groups relied on DFT calculations to suggest a reasonable supramolecular stacking of gelators, from which both structural and electronic information could be retrieved [30-34]. However, the computational requirements of the quantum mechanical DFT calculations limit the size of the system that can be tackled. Additionally, when the complexity of the molecular system increases, conformational space increases as well. For this reason, it is recommended that such computational studies consider only a simplified model of the gelator and are supported by experimental data. Apart from FT-IR and VCD spectra, the experimental UV-VIS spectra can be compared with the absorption spectra obtained from time-dependent DFT calculations (TD-DFT), strengthening the validity of the proposed stacking model [35,36]. In a more recent example, Zwijnenburg and co-workers relied on TD-DFT calculations to gain insight into the selfassembly and gelation of an alanine functionalized perylene bisimide gelator [37]. First, stable aggregates with different sizes (up to trimers) and protonation states were optimized at the DFT level. Subsequently, they obtained the respective TD-DFT computed UV-VIS spectra of the different structures. With these spectra, they were able to assign the changes in the experimental UV-VIS spectra during the glucono- $\delta$-lactone $\mathrm{pH}$-triggered gelation to a particular stacking of gelator molecules.
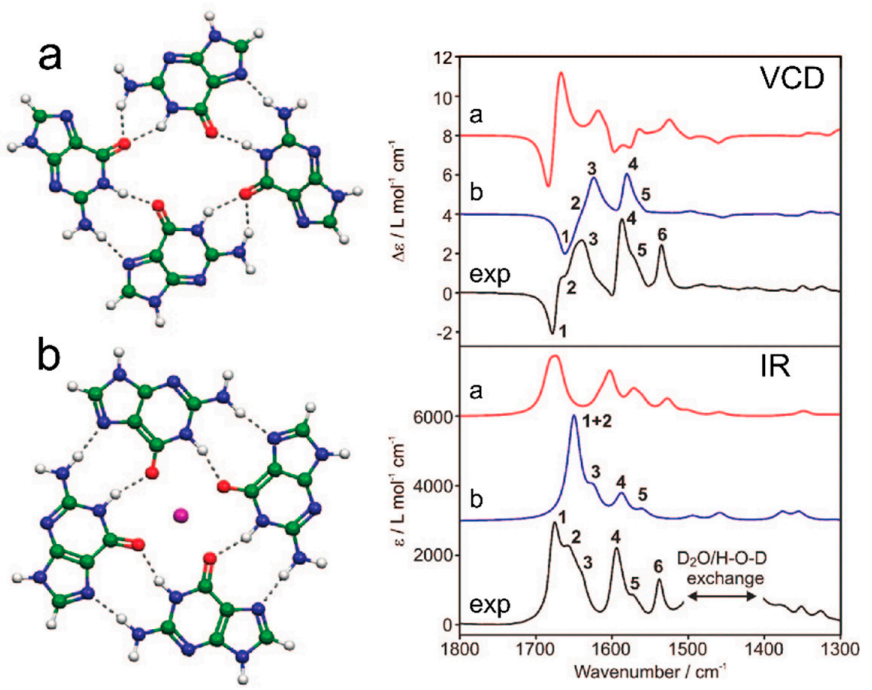

Figure 2. (a) A guanine quartet structure optimized at the B3LYP/6-31G** DFT level. (b) When a sodium ion is incorporated into the supramolecular stacking of the guanine derived hydrogelator model, a good agreement between the computed and experimental VCD and IR spectra could be obtained. Figure adapted with permission from ref. [28]. Copyright (2008) American Chemical Society. 
The accuracy that can be attained with DFT calculations goes hand in hand with significant computational requirements and size limitations. However, it has been shown that even calculations on a single gelator molecule, or a simplified model thereof, could provide valuable insights into the self-assembly behavior [13,38-40]. In 2013, Xie and co-workers were able to rationalize the gelation performance of a set of small pyridyl urea-based gelators through DFT calculations at the single gelator level [41]. Owing to the molecular simplicity of the gelator, they could perform a full conformational analysis on these structures. Surprisingly, when the pyridyl ring of the gelator was substituted in an ortho-fashion, conformations with an intramolecular hydrogen bond became accessible. These intramolecular interactions compete with the otherwise intermolecular urea hydrogen bonding, which is crucial for the self-assembly process. They rationalized that these observations could explain the drastic decrease in gelation performance when changing the substitution pattern of the pyridyl ring from para to ortho (Scheme 1). In addition, Wezenberg et al. showed the importance of intramolecular interactions on supramolecular gelation [42]. In their work, a photoswitchable urea-based gelator was developed. Interestingly, irradiation of the gelator with UV-light induced a trans-to-cis or cis-to-trans isomerization depending on the wavelength (Scheme 1). Furthermore, only the trans-isomer acts as an efficient gelator, making this system an effective photoswitchable supramolecular gel. By studying the possible conformations of both the trans- and cis-isomers via DFT calculations, they concluded that the absence of gelation characteristics of the cis-isomer could be rationalized by the formation of an intramolecular hydrogen bond. In previous examples, explicit intramolecular interactions disrupted gel formation. However, we recently showed, through static DFT calculations, that, depending on the molecular structure, intramolecular hydrogen bonding does not necessarily lead to the loss of gelation characteristics [13].
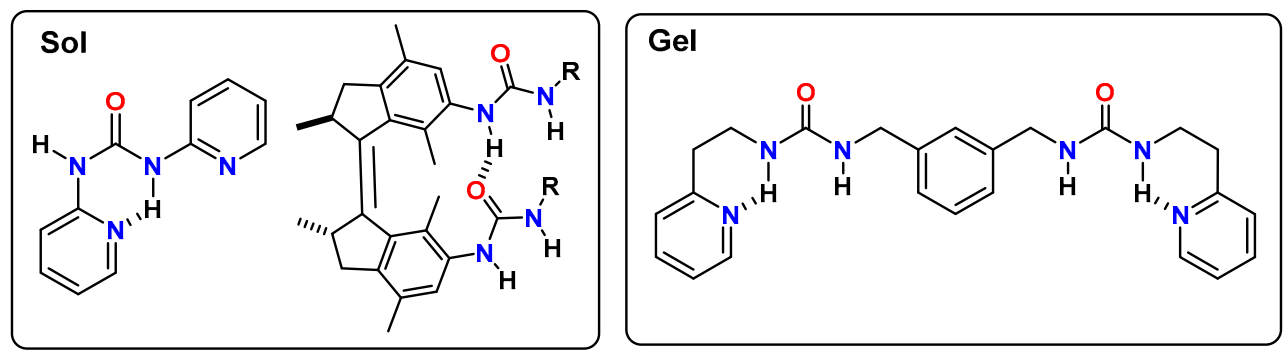

Scheme 1. Intramolecular hydrogen bonding can disrupt supramolecular gel formation in urea-based LMWGs (left), but not in all cases (right).

Apart from interactions in and between the gelator molecules, static QM calculations can be used to gain information on the strength and nature of explicit interactions between the gelator and an additive or the solvent $[40,43]$. In a collaborative effort of the Rai and Kundu groups, a variety of structures of a solvent molecule and a di-Fmoc-L-lysine gelator were optimized at the DFT level of theory [44]. A variety of combinations of the solvent molecule and the gelator were built based on insights from the electrostatic potential maps of the gelator and were able to elucidate different contributions to the gelator-solvent interactions, such as explicit hydrogen bonding. In addition, these calculations allowed to determine a pseudo cohesive energy density (PCED) of the gelator-solvent mixture as a measure of the binding energy per unit volume. By normalizing this value with the CED of the pure solvent, a parameter $\Lambda$ is obtained which quantifies the strength of the gelator-solvent interactions compared to the solvent-solvent interactions. Remarkably, their study shows that the value of $\Lambda$ has a qualitative correlation with the solubility behavior of the gelator in different solvents. 


\subsection{All-Atom Molecular Mechanics and Dynamic Simulations}

Molecular mechanics (MM) calculations are based on classical mechanics laws, with the relationship between the potential of a system and its topology described by a force field [45]. Because of the simplicity of most force field expressions, the computational workload of an MM calculation is significantly reduced, compared to a QM calculation on the exact same system. As can be expected, the performance of an MM calculation is highly dependent on the choice of force field, its parametrization and the accuracy thereof when describing the molecular system of interest. The fact that a multitude of different types of force fields exists, and more are constantly being developed, does not always make this easy for the end-user [46-51]. In this regard, special care must be taken when performing MM based calculations on supramolecular gels to ensure meaningful results. A proper choice of the force field and accurate parametrization can be obtained by comparison with experimental properties or computations performed at the QM level of theory.

Early research on supramolecular gels, in which MM computations were employed, featured static calculations as described in the previous section, involving single gelator molecules or small clusters to investigate possible stacking modes [52,53]. Nevertheless, as computational power increased and software was developed to take advantage of GPUacceleration, molecular dynamic (MD) simulations of larger supramolecular aggregates in explicit solvation became accessible [54-56]. For supramolecular gels, this specifically means that, at the moment, nano- to microsecond simulations of an aggregate containing hundreds of small gelator molecules are within reach with a modest GPU-based computing cluster [57]. While this time and length scale are still far too small to simulate and unveil the full self-assembly process taking place during gelation, two approaches currently exist to study this process by means of MD simulations: a top-down or a bottom-up approach (Figure 3) [15].

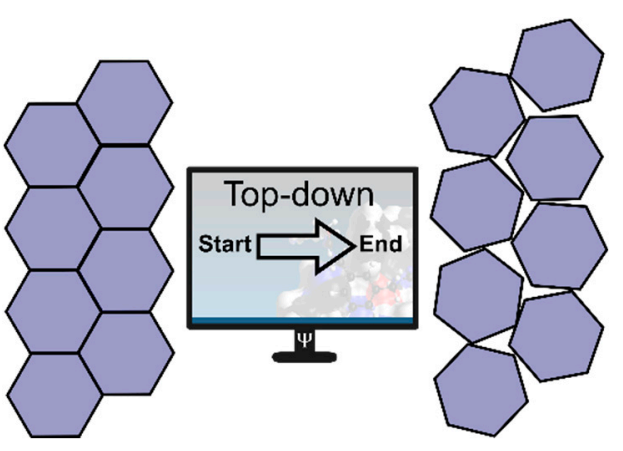

(a)

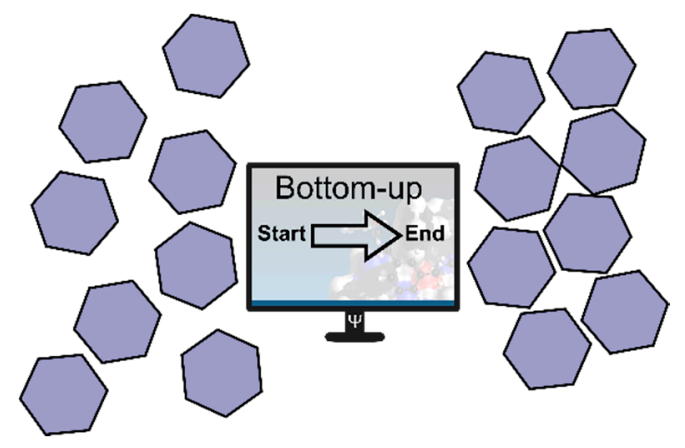

(b)

Figure 3. Similar to supramolecular polymerization, molecular dynamics simulations to study supramolecular gelation can either follow (a) a top-down scheme, in which the starting topology is a well-defined supramolecular aggregate of gelators, or (b) a bottom-up scheme, in which the starting topology consists of gelator molecules which are randomly dispersed in the simulation box.

In a top-down approach, the MD simulation starts from an organized supramolecular aggregate, of which the stability is probed by analyzing the topological changes occurring during the simulation. It is recommended that, instead of one, several properties are used to quantify the topological changes, such as the root-mean-square displacement of all atoms (RMSD), the solvent accessible surface area (SASA), the radius of gyration $\left(\mathrm{R}_{\mathrm{g}}\right)$, or other geometric parameters that might be unique for the aggregate [58]. If the proposed structure is unstable, atoms will diverge from one another and a reorganization of the structure will become apparent. On the other hand, if the proposed structure is stable, the relative position of the atoms in the structure will have little displacement along the trajectory and an equilibrated structure will be reached. Only supramolecular structures with a certain degree of stability are then considered to analyze plausible stacking modes 
that might be important during gelation [59-67]. The topology of the initial proposed structure is crucial to the value of this method. Moreover, while it can be challenging to propose an adequate initial structure based on chemical intuition, experimental data on the morphology of the gel network can help narrow down the possibilities and provide the necessary empirical validation.

In recent research published by the Steed group, a top-down MD approach was used to better understand how unique twisting ribbons were formed during the selfassembly of a pentakis(urea) based supramolecular gelator [68]. From TEM imaging, it was established that the gelator self-assembles into symmetrical twisted ribbons with a width of approximately 16-18 nm. Based on this experimental observation, a stacking model was constructed by having six 1-dimensional arrays of gelators with a helical pitch of $40 \mathrm{~nm}$. Crucially, this stacking model complied with the experimental morphological observations. Next, fibrils with 2, 3 or 4 of these layers were simulated for $2.5 \mathrm{~ns}$. From these simulations it became clear that only a structure containing 4 layers would be sufficiently stable during a $2.5 \mathrm{~ns}$ simulation (Figure 4). In this study, a conventional top-down MD approach was employed. However, in other cases, the proposed structure undergoes a significant reorganization. The same group used MD simulations in a previous study to investigate the self-assembly of a bis-urea based gelator [69]. Starting from an organized pre-stacked lamellar structure of the gelator, scrolling towards a cylindrical structure was observed. In another example, the Pavan group in collaboration with the Meier group used a top-down MD approach to elucidate the self-assembly of a 1,3,5-benzenetricarboxamide (BTA) derivative in water towards a supramolecular fiber [70]. The proposed aggregate for the simulation was built by sequential addition of pre-stacked structures that were optimized using DFT calculations and consisted of 48 molecules. The resulting fiber was placed in explicit water (TIP3P model) and underwent a dynamic simulation of $400 \mathrm{~ns}$. Notably, two folding stages were observed before an equilibrium structure was reached. In a first stage, the side chains of the BTA cores collapse around the core of the fiber to reduce the hydrophobic interactions between the fiber and the solvent, while in a second stage the fiber itself begins to fold, further minimizing the hydrophobic interactions. Only after 300 ns, an equilibrium structure is reached, underlining the importance of an adequate total simulation time when using a top-down MD approach.

In a bottom-up MD approach, the simulation starts from a random topology, preferably with the gelator molecules dispersed across the entire solvent medium. While computational limitations currently render it unfeasible to reach an equilibrated state using this approach, valuable insights can still be gained regarding the early self-assembly stage and specific non-covalent interactions driving supramolecular gelation [13,71]. While fewer of such studies exist, the Marlow and Zelzer group used a bottom-up MD approach to investigate the initial self-assembly of a nucleoside based gel at two different concentrations in an ethanol:water (20:80 v/v\%) mixture (Figure 5) [72]. At lower concentrations, smaller aggregates of the gelator were formed based on a parallel packing to maximize $\pi-\pi$ interactions. They also observed that the solvation around these aggregates was not homogeneous with the aliphatic tails mainly solvated by ethanol molecules, while the cytosine bases were mostly solvated by water. Prolongation of the simulation resulted in the reordering of these aggregates into a single flexible aggregate. When the concentration of the gelator was increased in the simulation box, similar results were obtained, although, in this case, an aggregate was formed that stretched across the periodic boundary of the box. In another study using a bottom-up MD approach, the Seddon and Adams groups investigated the packing of a small peptide based gelator (NapFF) in water [73]. More specifically, biased MD simulations starting from a dispersed state of NapFF molecules in water resulted in the formation of a hollow tubular aggregate of gelators. In this study, cylindrical restraints were introduced during the simulation to obtain an aggregate which would be consistent with the experimental scattering data. Upon relieving the restraints, the tubular structure did remain stable, due to the $\mathrm{Na}^{+}$ions present in the simulation box and hydrogen bonding within the structure. 

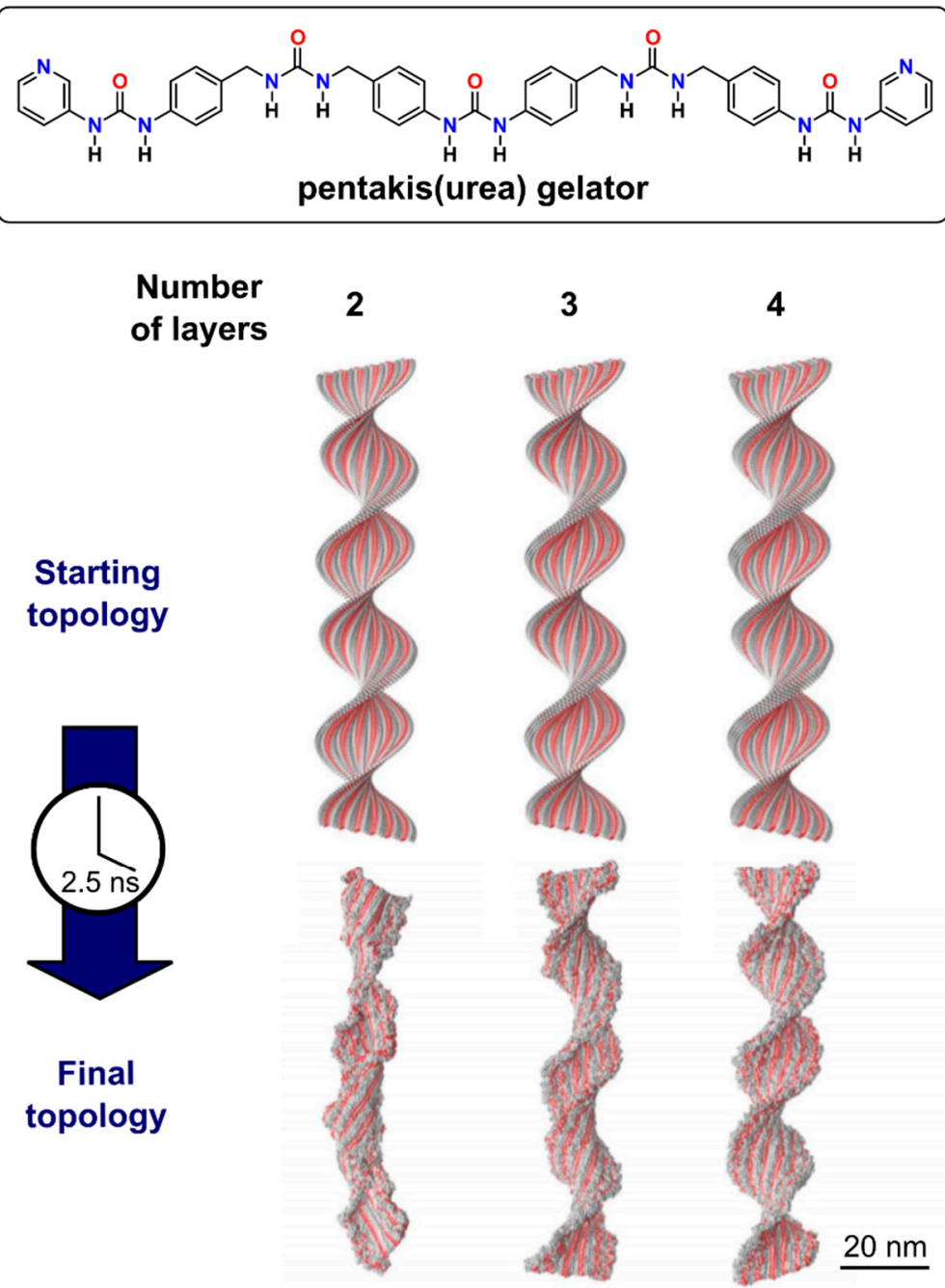

Figure 4. A stable stacking model for a pentakis(urea) gelator is obtained when 4 layers of six 1-dimensional arrays of these gelators are placed in a helical motif. Adapted by permission from ref. [68]. Copyright (2019) Springer Nature Customer Service Centre GmbH: Springer Nature, Nat. Chem.
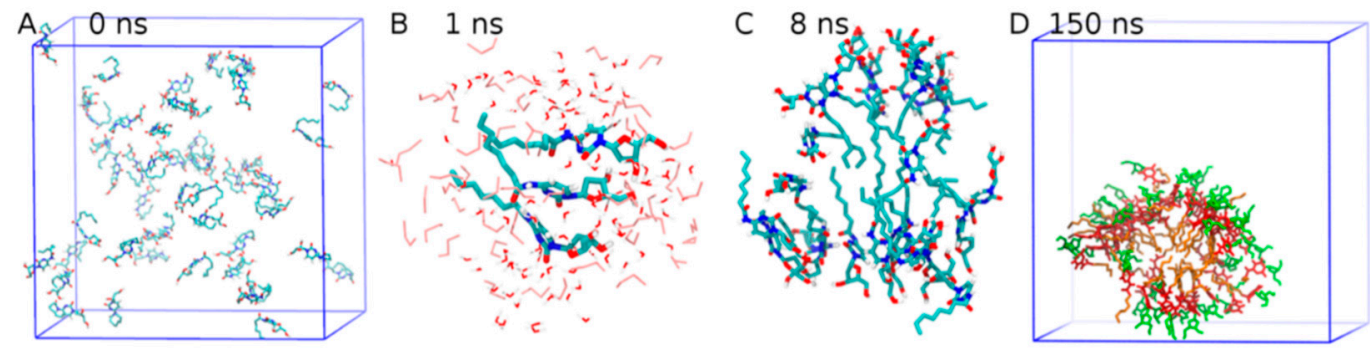

Figure 5. Snapshots from a bottom-up MD simulation tracking the early self-assembly of 50 nucleoside based gelators in a 20:80 v/v \% mixture of ethanol:water. Snapshots are taken at (A) the starting point ( $0 \mathrm{~ns})$ including randomly dispersed gelator molecules, (B) $1 \mathrm{~ns}$ at which small aggregates of parallel-aligned gelators can be observed, (C) $8 \mathrm{~ns}$ at which transient micellar structures can be observed and (D) at the end point (150 ns) displaying a micellar assembly. Reprinted with permission from ref. [72]. Copyright (2018) American Chemical Society. 


\subsection{United-Atom and Coarse-Grained Simulations}

The previously highlighted study showcases that geometrical constraints can be used to speed-up the self-assembly process during a bottom-up MD simulation. It is important, however, that these restraints are made based on a sound rationale. Another workaround to deal with limited computational power during a simulation is simplifying the force field that drives the dynamics. Indeed, the previously mentioned dynamic studies all used an all-atom force field expression to describe the gelators, in which each atom is explicitly parametrized. Simplified force field expressions can be obtained if multiple atoms are combined and treated as a single interacting site. One of the most popular methods that uses this approach is the united-atom potential, in which the hydrogen and carbon atoms of methyl or methylene groups are combined [74-79]. In addition, when describing supramolecular gels, a united-atom force field can be useful to increase the size- and time-scale of the simulation [80]. In a recent example, the Rai group used the transferable potentials for phase equilibria-united atom (TraPPE-UA) force field to investigate the aggregation of 12-hydroxyoctadecanamide in octane $[77,81]$. Thanks to the united-atom force field, they were able to run bottom-up MD simulations on 5001000 gelators in explicit octane $(12.5 \mathrm{wt} \%)$ for $500 \mathrm{~ns}$. With this time and length scale of simulation, they were able to observe the initial stage of fiber branching and reveal the importance of the hydroxyl group in the branching process.

More simplified potentials also exist, in which multiple atoms, depending on the functional group, are combined to a single interacting site. These potentials are referred to as coarse-grained (CG) force fields [82,83]. It is important to realize that the development of these CG potentials requires extensive efforts to ensure an adequate accuracy when describing the system, despite the significant loss of detail. In the case of supramolecular gels and biomolecular systems, the MARTINI CG force field is widely used due to its extensive development for the description of amino acids [84,85]. In 2012, the Schatz group used the MARTINI force field to model the self-assembly of the Ile-Lys-Val-Ala-Val (IKVAV) sequenced peptide amphiphile [86]. The CG MD simulations could reach up to several microseconds, which allowed them to observe spontaneous cylindrical fiber formation starting from a fully dispersed state of the peptides. Similarly, the Wei and Gazit groups made use of the MARTINI force field to investigate the self-assembly of a small peptidebased hydrogelator [87]. Similarly to the results obtained by Schatz and co-workers, the microseconds-long CG MD simulations enabled them to observe the self-assembly towards wormlike aggregates starting from a dispersed state. One obvious limitation to these approaches, however, is that due to the loss of atomistic details, it is not possible to directly correlate the self-assembly process to specific non-covalent interactions. To overcome this limitation, Nguyen and co-workers developed ePRIME, a CG model with intermediate resolution that combines enough detail to obtain insights into specific interactions, while pertaining computational tractability for the simulation of large systems [88]. In 2013, they used the ePRIME model to investigate the spontaneous self-assembly of peptide amphiphiles and to successfully construct phase diagrams that delineate morphological transitions triggered by external stimuli such as temperature [89]. Alternatively, one could opt to perform hybrid-resolution simulations, in which part of the system is described by a CG model, while other (more essential) parts are described by a united- or all-atom force field [90]. Finally, we note that some methods have been developed to retrieve the atomistic picture from the CG representation; however, they have yet to be tested in the field [91].

\subsection{Other Methods}

In addition to the archetypical static and dynamic computations mentioned above, other less conventional computational methods can be employed to gain valuable insights into the supramolecular gelation process. One such example is the Non-Covalent Interactions index (NCI). Developed in 2010 by the Yang group, the NCI allows for a 3-dimensional visualization of all non-covalent interactions in a molecular system, together with an indication of their strength [92-96]. While a full theoretical description of the NCI 
technique falls outside the scope of this review, it is important to recognize that the method can pinpoint noncovalent interactions in supramolecular gels, revealing their importance during gelation $[13,97,98]$. Briefly, the NCI method is based on the reduced density gradient and allows for the characterization and visualization of noncovalent interactions in real space. With current density functionals suffering from severe limitations in terms of generality for describing different types of noncovalent interactions, the NCI is extremely robust with respect to the computational method [99]. Indeed, some of the authors of this work have proven that the NCI method outperforms conventional methods to establish the hydrogen-bond network in proteins [100,101].

\section{Predicting Supramolecular Gelation}

From previous paragraphs, it became clear that computational tools can be used to study the self-assembly process that occurs during supramolecular gelation. Besides rationalization, researchers have dedicated their attention towards accelerating the discovery of novel supramolecular gels through computations. As a consequence, different methods have been proposed to predict the gelation propensity of a molecule in a solvent. While these methods differ in approach and applicability, they are all driven by computations and realize a reduction of chemical space, hence simplifying the selection of potential molecules that can gel a solvent.

\subsection{Predicition through the Crystal Structure}

In many ways, supramolecular gelation of a molecule in a solvent is related to its crystallization. Both supramolecular gelation and crystallization are non-equilibrium selfassembly processes that occur under supersaturated conditions and are characterized by a nucleation and growth phase [102,103]. For this reason, many experimental studies on supramolecular gels report powder X-ray diffraction data of the dried xerogel with the aim of extracting useful information on the structure of the gel network $[5,104,105]$. From the 1960s onwards, crystal structure prediction (CSP) has become a field on its own and has experienced an enormous development of applicable techniques able to predict the crystal morphology based on the molecular structure [106-110]. One strategy that has been explored to accelerate the design of new supramolecular gels is based on predicting the crystal structure of the gelator through a CSP method and, subsequently, analyzing if properties found in the predicted crystal morphology correlate to the gelation propensity of the molecule [111-115].

In 2016, the McNeil group successfully developed the first Pb-containing supramolecular gelators based on a method exploiting CSP (Figure 6) [116]. Starting from all Pbcontaining crystals available in the Cambridge Structural Database (CSD), a set of rational filters was applied to narrow down the scope to 352 structures. In the next step, molecular mechanics driven geometry optimizations further reduced the possible candidates to 184, which formed a set of workable size. Through generating a crystal graph for each compound, describing the interaction energy between the center of mass of one molecule with all other molecules in a preset sphere, the crystal morphology of all 184 compounds was predicted using the Growth Morphology software within Materials Studio [117]. After this, the aspect ratio was computed for all predicted crystal morphologies, by taking the ratio of the longest distance within the crystal to the shortest distance. Finally, two compounds were selected for derivatization and gel screening, by looking at the predicted crystal structures with the highest aspect ratio (top 5\%) and with ease of chemical synthesis in mind. As a result of this approach, a first class of $6 \mathrm{~Pb}$-containing supramolecular gelators was designed, out of which one was explored for its ability to sense $\mathrm{Pb}^{2+}$ in paint.

While the work of the McNeil group showcases the potential of using CSP to accelerate the development of supramolecular gelators, we do want to emphasize that one must be critical when scrutinizing data related to the crystal structure to draw conclusions on the corresponding supramolecular gelation process. Albeit the crystalline- and supramolecular gelation process are related to some extent, it has been pointed out, on several occasions, 
that the crystal structure of a molecule can significantly differ from the stacking mode and noncovalent interactions present in its gel phase [118-120].

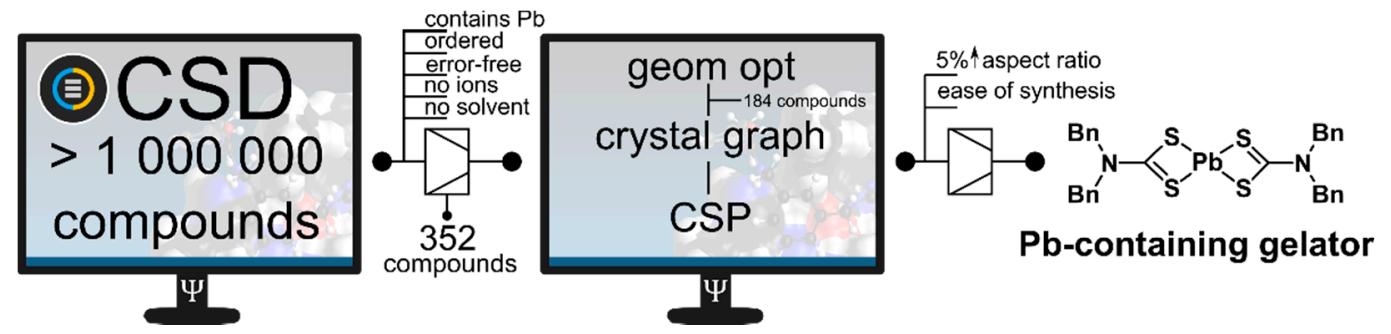

Figure 6. Schematic overview of the CSP-based approach used by the McNeil group to develop the first Pb-containing supramolecular gelators [112].

\subsection{Solvent Parameters}

In most supramolecular gels, the solvent makes up $99 \%$ of the material or even more. Evidently, one can expect that the properties of the supramolecular gel are highly dependent on the solvent. As a consequence, many groups have analyzed possible correlations between gel propensity or properties of the gel phase and intrinsic parameters of the solvent, such as the solvent dielectric constant, polarity parameter $\mathrm{E}_{\mathrm{T}}(30)$, the Kamlet-Taft solvent parameters or the Hildebrand solubility parameter [121-127]. Over the years, the Hanssen solubility parameters (HSPs) have proven to be highly useful when investigating complex solvation effects or predicting gelable solvents [128-131]. Briefly, the HSPs are a result from the decomposition of the Hildebrand solubility parameter into three contributing molecular interactions: dispersive interactions $\left(\delta_{\mathrm{d}}\right)$, polar interactions $\left(\delta_{\mathrm{p}}\right)$ and hydrogenbonding interactions $\left(\delta_{\mathrm{h}}\right)$ [132]. Originally intended for selecting solvents for polymeric systems, the Bouteiller group was the first to successfully manipulate the HSPs to predict gelable solvents for a specific supramolecular gelator [133-135]. In their approach, an initial solubility dataset is constructed by testing the gelation behavior of a gelator in various solvents. Results are classified into three categories: the molecule is soluble in the solvent $(\mathrm{S})$, gels the solvent $(\mathrm{G})$, or forms a precipitate $(\mathrm{P})$. Based on this dataset, a solubility sphere and one or more gelation spheres are defined in the Hansen space. The radius and center of these spheres are determined by an optimization which results in having most $S$ points inside the solubility sphere but outside the gelation sphere (s), most $G$ points inside the gelation sphere(s) but outside the solubility sphere and most $P$ points outside both the solubility and gelation spheres. In this manner, the solubility behavior of the gelator in an untested solvent can be easily predicted based on the location of the solvent in Hansen space.

Further investigations revealed that the method described above could be improved and simplified by allowing a single solubility and gelation sphere to overlap (Figure 7) [129,136-138]. The Rogers group had a notable impact in further development of this methodology [139-141]. In a more recent work from the group, the values of the radius and center of the constructed gelation sphere were used to elucidate the ability and driving forces behind the gelation of different peptide-based supramolecular gelators [142]. The gelation sphere obtained for $L$-diphenylalanine $(L-F F)$ was centered around the values of $2 \delta_{\mathrm{d}}=32.80 \mathrm{MPa}^{1 / 2}$, $\delta_{\mathrm{p}}=8.70 \mathrm{MPa}^{1 / 2}$ and $\delta_{\mathrm{h}}=11.50 \mathrm{MPa}^{1 / 2}$ and had a radius of $5.61 \mathrm{MPa}^{1 / 2}$. On the other hand, the gelation sphere for $L$-dityrosine $(L-Y Y)$ was centered around $2 \delta_{\mathrm{d}}=31.39 \mathrm{MPa}^{1 / 2}$, $\delta_{\mathrm{p}}=15.75 \mathrm{MPa}^{1 / 2}$ and $\delta_{\mathrm{h}}=14.65 \mathrm{MPa}^{1 / 2}$ and had a radius of $18.50 \mathrm{MPa}^{1 / 2}$. The increased radius of the gelation sphere of $L-Y Y$ in comparison to $L-F F$, highlights the greater gelation capacity of $L-Y Y$. Moreover, the shift of the gelation sphere towards more polar and greater hydrogen bonding solvents when going from $L$-FF to $L-Y Y$ underlines the change in the driving force behind gelation towards polar interactions and hydrogen bonding upon including additional hydroxyl groups to the structure. 


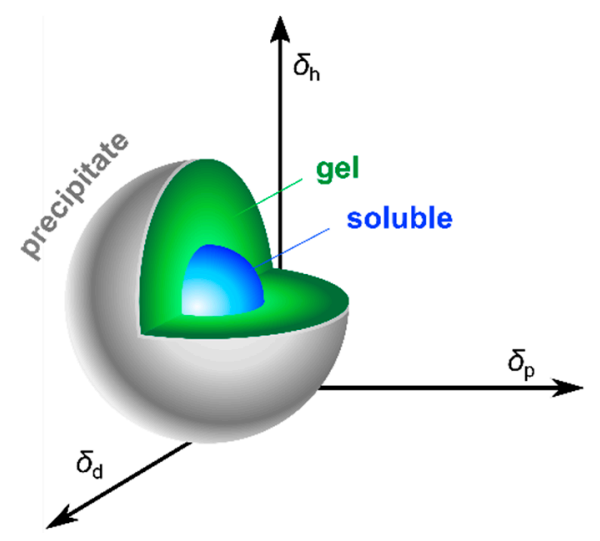

Figure 7. Schematic representation of a solubility sphere and gelation sphere in Hansen space. Most accurate and uncomplicated models allow the solubility and gelation sphere to overlap. Note that it is not necessary to achieve the best results by having the centers of both spheres coincide as is depicted herein.

\subsection{Molecular Dynamics and Machine Learning}

Whilst the value of the HSP method described above is obvious from the many studies on supramolecular gels that rely on the technique, it does require extensive laborious efforts, as a large collection of experimental gelation data needs to be gathered beforehand. To further accelerate the discovery of new potential gelators, it would be beneficial to be able to predict the gelation propensity of a molecule before stepping into the lab. In this section, a number of strategies are highlighted that can evaluate the gelation propensity of a molecule, solely based on the molecular structure of the gelator.

A significant contribution towards the prediction of supramolecular gelation was made by the collaborative efforts from the Tuttle and Ulijn groups [143]. Already in 2011, they proposed an aggregation propensity score (AP) able to quantify the aggregation tendency of a given peptide [144]. More specifically, starting from a fully dispersed state, coarse-grained simulations are performed to track the self-assembly behavior of a small peptide. Next, the AP score is computed by taking the ratio of the solvent accessible surface area (SASA) of the peptides at the initial topology to the SASA of the peptides at the end of the simulation. An AP value greater than 2 is arbitrarily proposed as an indication of a high degree of aggregation. Four years later, they reported a corrected AP score $\left(A P_{H}\right)$, which incorporates the hydrophilicity of the peptide by multiplying the original AP score with a computed $\log$ P value [145]. Notably, they screened over 8000 tripeptides and successfully showed that this hydrophilicity-corrected $\mathrm{AP}_{\mathrm{H}}$ score can be used as a reliable descriptor to create a set of design rules for the development of new peptide-based hydrogelators. We believe the success of their approach can largely be attributed to the physical relevance of the proposed descriptor towards describing the self-assembly process.

Another approach to predict supramolecular gelation relies on machine learning schemes. Based on collected experimental data and a large descriptor set, the Adams and Berry group were the first to successfully train a number of machine learning models able to accurately classify dipeptide systems into efficient hydrogelators and nonhydrogelators [146]. Remarkably, the prediction is based on a variety of physicochemical properties and molecular fingerprints that are generated based on the simplified molecularinput line-entry specification (SMILES) representation of the gelator. This allowed for a high-throughput prediction, as long as the SMILES code falls within the applicability domain of the model. While chemical intuition does not initially link the descriptors used to build the model to the gelation process, the work is an excellent example of how different machine learning techniques can exploit large amounts of data and retrieve complex relationships between them. In addition, the Fok and Li groups adapted a similar machine learning approach to predict the gelation propensity of dipeptide hydrogelators [147]. 
Recently, our group developed a set of descriptors, which can all be obtained from all-atom molecular dynamics simulations [148]. The relative solvent accessible surface area (rSASA) quantifies aggregation of the gelators, the relative end-to-end distance ( $\mathrm{rH}$ ) describes the flexibility and conformational preference of the gelators, the hydrogen bonding percentage $(\mathrm{HB} \%)$ measures the noncovalent linkage between gelator molecules through hydrogen bonding and the shape factor $(\mathrm{F})$ describes the aggregate's shape. These descriptors are of fundamental value to the gelation process, but more importantly they can be used to optimize machine learning models that are able to classify combinations of a urea-based gelator and a number of solvents into three categories. Either the gelator is soluble in the solvent, forms a precipitate or gels the solvent (Figure 8). Notably, this is the same classification that is obtained from the HSP method described earlier. Due to their relevance in describing the self-assembly that occurs during the simulation, we anticipate these descriptors to be valuable for different types of supramolecular gelators. One drawback to the method, however, is that extensive MD simulations need to be performed to obtain the descriptor, limiting the throughput of prediction.

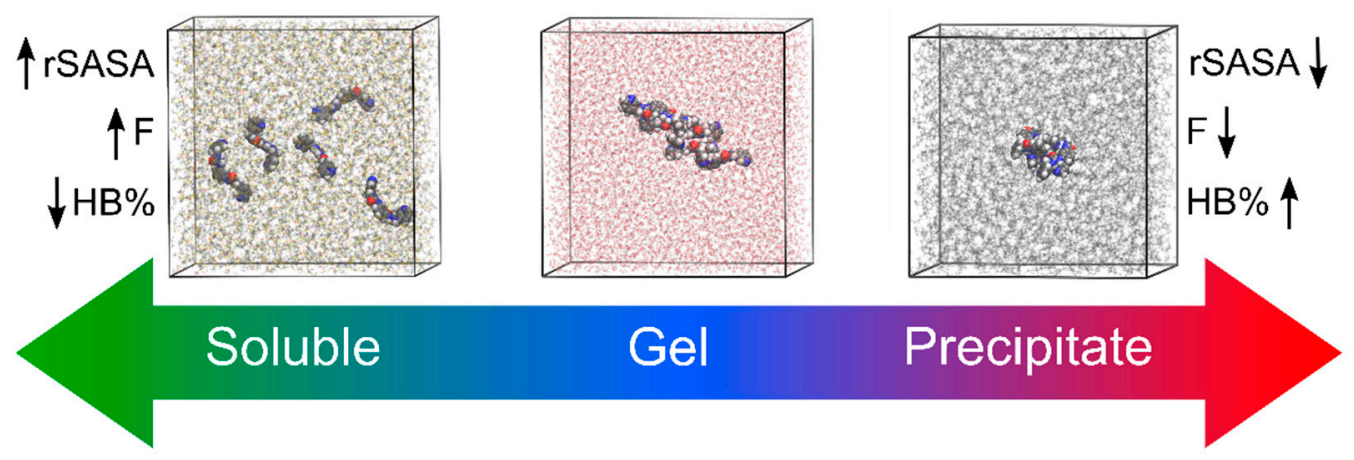

Figure 8. Descriptors obtained from MD simulations can help analyze and predict the outcome of gelation test into three categories. Either the molecule is soluble in the solvent, gels the solvent or forms a precipitate. Reprinted with permission from ref. [144]. Copyright (2011) The Royal Society of Chemistry.

\section{Conclusions and Future Perspectives}

In this review, we discussed the potential of computational methods within the field of supramolecular gels. A thorough examination of the studies performed on supramolecular gels in the past two decades revealed that computational methods can improve our fundamental understanding of the self-assembly behavior of supramolecular gels. Different computational techniques were introduced that can provide insights on different time and length scales of the supramolecular gelation process. A combination of multiple computational methods integrated into a multiscale approach provides the most complete picture, complementary to well-established wet-lab experiments. In addition to rationalization, computational tools have shown the ability to accelerate the development of supramolecular gels, by defining boundaries around a specific area of chemical space and simplifying the selection of possible gelator candidates through various approaches. This review attempts to create awareness on the added value of computational chemistry when investigating supramolecular gels, as well as provide an overview of the current possibilities and state-of-the-art.

As the field moves forward, we believe the use of computational methods will become even more prominent when studying supramolecular gels. In the upcoming years, the ever-increasing computing power will enable researchers to perform calculations with an accuracy that was previously considered unattainable [149]. For supramolecular gels specifically, this could mean investigating larger molecular events, such as fiber entanglement, with atomistic precision. Another challenge the field faces is creating a more efficient discovery process for supramolecular gels with real-life use. A variety of potential 
applications are explored for these soft materials, with each application requiring specific material properties. Obtaining a priori knowledge on the tunability of these material properties, would drastically change the development strategy of supramolecular gels and could enable them to have a tangible impact on society. One approach, currently being heavily explored for the directed design of other next generation materials, is establishing quantitative structure-property relationships by means of machine learning [150-155]. In previous paragraphs, we already touched on the use of machine learning models to facilitate the discovery of gelators [146-148]. In this regard, collecting material properties of different supramolecular gels that are obtained through a consistent and unambiguous manner in a central and open database would greatly expedite the search for quantitative structure-property relationships through machine learning.

Author Contributions: The manuscript was written by R.V.L. with input from W.M.D.B., F.D.P. and M.A. All authors have read and agreed to the published version of the manuscript.

Funding: This research was funded by FWO, grant number $1185221 \mathrm{~N}$, as well as the postdoctoral fellowship 12F4416N.

Acknowledgments: R.V.L. thanks the FWO for the PhD fellowship received. M.A. thanks the FWO for a postdoctoral fellowship and the VUB for financial support. F.D.P. acknowledges the Strategic Research Program funding of the VUB.

Conflicts of Interest: The authors declare no conflict of interest.

\section{References}

1. Draper, E.R.; Adams, D.J. Low-Molecular-Weight Gels: The State of the Art. Chem 2017, 3, 390-410. [CrossRef]

2. Weiss, R.G. The Past, Present, and Future of Molecular Gels. What Is the Status of the Field, and Where Is It Going? J. Am. Chem. Soc. 2014, 136, 7519-7530. [CrossRef]

3. Du, X.W.; Zhou, J.; Shi, J.F.; Xu, B. Supramolecular Hydrogelators and Hydrogels: From Soft Matter to Molecular Biomaterials. Chem. Rev. 2015, 115, 13165-13307. [CrossRef]

4. Chivers, P.R.A.; Smith, D.K. Shaping and structuring supramolecular gels. Nat. Rev. Mater. 2019, 4, 463-478. [CrossRef]

5. Yu, G.; Yan, X.; Han, C.; Huang, F. Characterization of Supramolecular Gels. Chem. Soc. Rev. 2013, 42, 6697-6722. [CrossRef]

6. Dawn, A.; Kumari, H. Low Molecular Weight Supramolecular Gels Under Shear: Rheology as the Tool for Elucidating StructureFunction Correlation. Chem. A Eur. J. 2017, 24, 762-776. [CrossRef]

7. Escuder, B.; Llusar, M.; Miravet, J.F. Insight on the NMR Study of Supramolecular Gels and Its Application to Monitor Molecular Recognition on Self-Assembled Fibers. J. Org. Chem. 2006, 71, 7747-7752. [CrossRef] [PubMed]

8. Kubota, R.; Nakamura, K.; Torigoe, S.; Hamachi, I. The Power of Confocal Laser Scanning Microscopy in Supramolecular Chemistry: In situ Real-time Imaging of Stimuli-Responsive Multicomponent Supramolecular Hydrogels. ChemistryOpen 2020, 9 , 67-79. [CrossRef]

9. Müller-Dethlefs, K.; Hobza, P. Noncovalent Interactions: A Challenge for Experiment and Theory. Chem. Rev. 2000, 100, 143-168. [CrossRef]

10. Al-Hamdani, Y.S.; Tkatchenko, A. Understanding Non-Covalent Interactions in Larger Molecular Complexes from First Principles. J. Chem. Phys. 2019, 150, 010901. [CrossRef]

11. Yan, S.; Lee, S.J.; Kang, S.; Lee, J.Y. Computational Approaches in Molecular Recognition, Self-assembly, Electron Transport, and Surface Chemistry. Supramol. Chem. 2007, 19, 229-241. [CrossRef]

12. Li, Y.; Sun, Y.; Qin, M.; Cao, Y.; Wang, W. Mechanics of single peptide hydrogelator fibrils. Nanoscale 2015, 7, 5638-5642. [CrossRef] [PubMed]

13. Van Lommel, R.; Rutgeerts, L.A.J.; De Borggraeve, W.M.; De Proft, F.; Alonso, M. Rationalising Supramolecular Hydrogelation of Bis-Urea-Based Gelators through a Multiscale Approach. ChemPlusChem 2020, 85, 267-276. [CrossRef] [PubMed]

14. Gooneie, A.; Schuschnigg, S.; Holzer, C. A Review of Multiscale Computational Methods in Polymeric Materials. Polymers 2017, 9, 16. [CrossRef] [PubMed]

15. Bochicchio, D.; Pavan, G.M. Molecular modelling of supramolecular polymers. Adv. Phys. X 2018, 3, 1436408. [CrossRef]

16. Jensen, F. Introduction to Computational Chemistry; John Wiley \& Sons: Hoboken, NJ, USA, 2006.

17. Calbo, J.; Sancho-García, J.C.; Ortí, E.; Aragó, J. Quantum-Chemical Insights into the Self-Assembly of Carbon-Based Supramolecular Complexes. Molecules 2018, 23, 118. [CrossRef] [PubMed]

18. Grimme, S.; Antony, J.; Schwabe, T.; Mück-Lichtenfeld, C. Density functional theory with dispersion corrections for supramolecular structures, aggregates, and complexes of (bio)organic molecules. Org. Biomol. Chem. 2007, 5, 741-758. [CrossRef] [PubMed]

19. Cho, Y.; Cho, W.J.; Youn, I.S.; Lee, G.; Singh, N.J.; Kim, K.S. Density Functional Theory Based Study of Molecular Interactions, Recognition, Engineering, and Quantum Transport in $\pi$ Molecular Systems. Acc. Chem. Res. 2014, 47, 3321-3330. [CrossRef] 
20. Kristyán, S.; Pulay, P. Can (semi)local density functional theory account for the London dispersion forces? Chem. Phys. Lett. 1994, 229, 175-180. [CrossRef]

21. Hobza, P.; Sponer, J.; Reschel, T. Density functional theory and molecular clusters. J. Comput. Chem. 1995, 16, 1315-1325. [CrossRef]

22. DiLabio, G.A.; Otero-De-La-Roza, A. Noncovalent Interactions in Density Functional Theory. Rev. Comput. Chem. 2016, 1-97. [CrossRef]

23. Mardirossian, N.; Head-Gordon, M. Thirty years of density functional theory in computational chemistry: An overview and extensive assessment of 200 density functionals. Mol. Phys. 2017, 115, 2315-2372. [CrossRef]

24. Chai, J.D.; Head-Gordon, M. Long-range corrected hybrid density functionals with damped atom-atom dispersion corrections. Phys. Chem. Chem. Phys. 2008, 10, 6615-6620. [CrossRef] [PubMed]

25. Grimme, S.; Antony, J.; Ehrlich, S.; Krieg, H. A consistent and accurate ab initio parametrization of density functional dispersion correction (DFT-D) for the 94 elements H-Pu. J. Chem. Phys. 2010, 132, 154104. [CrossRef]

26. Vydrov, O.A.; Van Voorhis, T. Nonlocal van der Waals density functional: The simpler the better. J. Chem. Phys. 2010, 133, 244103. [CrossRef]

27. Calbo, J.; Ortí, E.; Sancho-Garcia, J.C.; Aragó, J. Accurate Treatment of Large Supramolecular Complexes by Double-Hybrid Density Functionals Coupled with Nonlocal van der Waals Corrections. J. Chem. Theory Comput. 2015, 11, 932-939. [CrossRef] [PubMed]

28. Setnička, V.; Nový, J.; Böhm, S.; Sreenivasachary, N.; Urbanová, M.; Volka, K. Molecular Structure of Guanine-Quartet Supramolecular Assemblies in a Gel-State Based on a DFT Calculation of Infrared and Vibrational Circular Dichroism Spectra. Langmuir 2008, 24, 7520-7527. [CrossRef]

29. Hoogsteen, K. The crystal and molecular structure of a hydrogen-bonded complex between 1-methylthymine and 9methyladenine. Acta Crystallogr. 1963, 16, 907-916. [CrossRef]

30. Li, J.; Fan, K.; Niu, L.; Li, Y.; Song, J. Effects of Salt on the Gelation Mechanism of a d-Sorbitol-Based Hydrogelator. J. Phys. Chem. B 2013, 117, 5989-5995. [CrossRef]

31. Schön, E.-M.; Marqués-López, E.; Herrera, R.P.; Alemán, C.; Díaz, D.D. Exploiting Molecular Self-Assembly: From Urea-Based Organocatalysts to Multifunctional Supramolecular Gels. Chem. A Eur. J. 2014, 20, 10720-10731. [CrossRef]

32. Draper, E.R.; Schweins, R.; Akhtar, R.; Groves, P.; Chechik, V.; Zwijnenburg, M.A.; Adams, D.J. Reversible Photoreduction as a Trigger for Photoresponsive Gels. Chem. Mater. 2016, 28, 6336-6341. [CrossRef]

33. Vega-Granados, K.; Ramírez-Rodríguez, G.B.; Contreras-Montoya, R.; Ramírez, F.J.; Palomo, L.; Parra, A.; Delgado-López, J.M.; Lopez-Lopez, M.T.; De Cienfuegos, L.Á. Atmospheric water triggers supramolecular gel formation of novel low molecular weight maslinic and oleanolic triterpenic derivatives. Mater. Chem. Front. 2019, 3, 2637-2646. [CrossRef]

34. Xu, F.; Pfeifer, L.; Crespi, S.; Leung, F.K.-C.; Stuart, M.C.A.; Wezenberg, S.J.; Feringa, B.L. From Photoinduced Supramolecular Polymerization to Responsive Organogels. J. Am. Chem. Soc. 2021, 143, 5990-5997. [CrossRef]

35. Draper, E.R.; Greeves, B.J.; Barrow, M.; Schweins, R.; Zwijnenburg, M.A.; Adams, D.J. pH-Directed Aggregation to Control Photoconductivity in Self-Assembled Perylene Bisimides. Chem 2017, 2, 716-731. [CrossRef]

36. Gainar, A.; Lai, T.L.; Oliveras-González, C.; Pop, F.; Raynal, M.; Isare, B.; Bouteiller, L.; Linares, M.; Canevet, D.; Avarvari, N.; et al. Tuning the Organogelating and Spectroscopic Properties of a C 3-Symmetric Pyrene-Based Gelator through Charge Transfer. Chem. A Eur. J. 2021, 27, 2410-2420. [CrossRef]

37. Draper, E.R.; Wilbraham, L.; Adams, D.J.; Wallace, M.; Schweins, R.; Zwijnenburg, M.A. Insight into the self-assembly of water-soluble perylene bisimide derivatives through a combined computational and experimental approach. Nanoscale 2019, 11, 15917-15928. [CrossRef] [PubMed]

38. Piana, F.; Case, D.H.; Ramalhete, S.M.; Pileio, G.; Facciotti, M.; Day, G.M.; Khimyak, Y.Z.; Angulo, J.; Brown, R.C.D.; Gale, P.A. Substituent interference on supramolecular assembly in urea gelators: Synthesis, structure prediction and NMR. Soft Matter 2016, 12, 4034-4043. [CrossRef] [PubMed]

39. Kumar, A.; Dubey, M.; Kumar, A.; Pandey, D.S. A Saponification-Triggered Gelation of Ester-Based Zn(ii) Complex through Conformational Transformations. Chem. Commun. 2014, 50, 10086-10089. [CrossRef] [PubMed]

40. Meng, S.C.; Li, W.; Yin, X.L.; Xie, J.M. A comprehensive theoretical study of the hydrogen bonding interactions and microscopic solvation structures of a pyridyl-urea-based hydrogelator in aqueous solution. Comput. Theor. Chem. 2013, 1006, 76-84. [CrossRef]

41. Meng, S.C.; Tang, Y.Q.; Yin, Y.; Yin, X.L.; Xie, J.M. A theoretical study of molecular conformations and gelation ability of N,N'-dipyridyl urea compounds in ethanol solution: DFT calculations and MD simulations. RSC Adv. 2013, 3, 18115. [CrossRef]

42. Wezenberg, S.J.; Croisetu, C.M.; Stuart, M.C.A.; Feringa, B.L. Reversible gel-sol photoswitching with an overcrowded alkenebased bis-urea supergelator. Chem. Sci. 2016, 7, 4341-4346. [CrossRef]

43. Ghosh, D.; Bjornsson, R.; Damodaran, K.K. Role of N-Oxide Moieties in Tuning Supramolecular Gel-State Properties. Gels 2020, 6, 41. [CrossRef] [PubMed]

44. Hashemnejad, S.M.; Huda, M.M.; Rai, N.; Kundu, S. Molecular Insights into Gelation of Di-Fmoc-l-Lysine in Organic SolventWater Mixtures. ACS Omega 2017, 2, 1864-1874. [CrossRef] [PubMed]

45. Frenkel, D.; Smit, B. Understanding Molecular Simulation; Academic Press: Cambridge, MA, USA, 2001.

46. Salomon-Ferrer, R.; Case, D.A.; Walker, R.C. An overview of the Amber biomolecular simulation package. Wiley Interdiscip. Rev. Comput. Mol. Sci. 2013, 3, 198-210. [CrossRef] 
47. Jorgensen, W.L.; Tirado-Rives, J. Potential energy functions for atomic-level simulations of water and organic and biomolecular systems. Proc. Natl. Acad. Sci. USA 2005, 102, 6665-6670. [CrossRef] [PubMed]

48. Foloppe, N.; MacKerell, A.D., Jr. All-Atom Empirical Force Field for Nucleic Acids: I. Parameter Optimization based on Small Molecule and Condensed Phase Macromolecular Target Data. J. Comput. Chem. 2000, 21, 86-104. [CrossRef]

49. Vanommeslaeghe, K.; Hatcher, E.; Acharya, C.; Kundu, S.; Zhong, S.; Shim, J.; Darian, E.; Guvench, O.; Lopes, P.; Vorobyov, I.; et al. Charmm general force field: A force field for drug-like molecules compatible with the charmm all-atom additive biological force fields. J. Comput. Chem. 2009, 31, 671-690. [CrossRef]

50. Wang, J.; Wolf, R.M.; Caldwell, J.W.; Kollman, P.A.; Case, D.A. Development and testing of a general amber force field. J. Comput. Chem. 2004, 25, 1157-1174. [CrossRef]

51. Halgren, T.A. Merck Molecular Force Field. I. Basis, Form, Scope, Parameterization, and Performance of MMFF94. J. Comput. Chem. 1996, 17, 490-519. [CrossRef]

52. van Esch, J.H.; Schoonbeek, F.; de Loos, M.; Kooijman, H.; Spek, A.L.; Kellogg, R.M.; Feringa, B.L. Cyclic Bis-Urea Compounds as Gelators for Organic Solvents. Chem. A Eur. J. 1999, 5, 937-950. [CrossRef]

53. Mallia, V.A.; George, M.; Blair, D.L.; Weiss, R.G. Robust Organogels from Nitrogen-Containing Derivatives of (R)-12Hydroxystearic Acid as Gelators: Comparisons with Gels from Stearic Acid Derivativest. Langmuir 2009, 25, 8615-8625. [CrossRef]

54. Abraham, M.J.; Murtola, T.; Schulz, R.; Páll, S.; Smith, J.C.; Hess, B.; Lindahl, E. GROMACS: High performance molecular simulations through multi-level parallelism from laptops to supercomputers. SoftwareX 2015, 1-2, 19-25. [CrossRef]

55. Kutzner, C.; Páll, S.; Fechner, M.; Esztermann, A.; de Groot, B.L.; Grubmüller, H. More bang for your buck: Improved use of GPU nodes for GROMACS 2018. J. Comput. Chem. 2019, 40, 2418-2431. [CrossRef] [PubMed]

56. Frederix, P.W.J.M.; Patmanidis, I.; Marrink, S.J. Molecular simulations of self-assembling bio-inspired supramolecular systems and their connection to experiments. Chem. Soc. Rev. 2018, 47, 3470-3489. [CrossRef] [PubMed]

57. Alegre-Requena, J.V.; Saldías, C.; Inostroza-Rivera, R.; Díaz, D.D. Understanding Hydrogelation Processes through Molecular Dynamics. J. Mater. Chem. B 2019, 7, 1652-1673. [CrossRef]

58. Knapp, B.; Frantal, S.; Cibena, M.; Schreiner, W.; Bauer, P. Is an Intuitive Convergence Definition of Molecular Dynamics Simulations Solely Based on the Root Mean Square Deviation Possible? J. Comput. Biol. 2011, 18, 997-1005. [CrossRef] [PubMed]

59. Smith, A.M.; Williams, R.J.; Tang, C.; Coppo, P.; Collins, R.F.; Turner, M.L.; Saiani, A.; Ulijn, R.V. Fmoc-Diphenylalanine Self Assembles to a Hydrogel via a Novel Architecture Based on $\pi-\pi$ Interlocked $\beta$-Sheets. Adv. Mater. 2008, 20, 37-41. [CrossRef]

60. Drechsler, S.; Balog, S.; Kilbinger, A.F.M.; Casalini, T. The influence of substituents on gelation and stacking order of oligoaramidBased supramolecular networks. Soft Matter 2019, 15, 7250-7261. [CrossRef]

61. Parisi, E.; Garcia, A.M.; Marson, D.; Posocco, P.; Marchesan, S. Supramolecular Tripeptide Hydrogel Assembly with 5-Fluorouracil. Gels 2019, 5, 5. [CrossRef]

62. Eckes, K.M.; Mu, X.; Ruehle, M.A.; Ren, P.; Suggs, L.J. $\beta$ Sheets Not Required: Combined Experimental and Computational Studies of Self-Assembly and Gelation of the Ester-Containing Analogue of an Fmoc-Dipeptide Hydrogelator. Langmuir 2014, 30, 5287-5296. [CrossRef]

63. Mu, X.; Eckes, K.M.; Nguyen, M.M.; Suggs, L.J.; Ren, P. Experimental and Computational Studies Reveal an Alternative Supramolecular Structure for Fmoc-Dipeptide Self-Sssembly. Biomacromolecules 2012, 13, 3562-3571. [CrossRef]

64. Nguyen, M.M.; Eckes, K.M.; Suggs, L.J. Charge and sequence effects on the self-assembly and subsequent hydrogelation of Fmoc-depsipeptides. Soft Matter 2014, 10, 2693-2702. [CrossRef]

65. Lee, O.-S.; Stupp, S.I.; Schatz, G.C. Atomistic Molecular Dynamics Simulations of Peptide Amphiphile Self-Assembly into Cylindrical Nanofibers. J. Am. Chem. Soc. 2011, 133, 3677-3683. [CrossRef] [PubMed]

66. Zhang, W.; Zhang, Z.; Zhao, S.; Hong, K.H.; Zhang, M.-Y.; Song, L.; Yu, F.; Luo, G.; He, Y.-P. Pyromellitic-Based Low Molecular Weight Gelators and Computational Studies of Intermolecular Interactions: A Potential Additive for Lubricant. Langmuir 2021, 37, 2954-2962. [CrossRef] [PubMed]

67. Wychowaniec, J.K.; Patel, R.; Leach, J.; Mathomes, R.; Chhabria, V.; Patil-Sen, Y.; Hidalgo-Bastida, A.; Forbes, R.T.; Hayes, J.M.; ElSawy, M.A. Aromatic Stacking Facilitated Self-Assembly of Ultrashort Ionic Complementary Peptide Sequence: $\beta$-Sheet Nanofibers with Remarkable Gelation and Interfacial Properties. Biomacromolecules 2020, 21, 2670-2680. [CrossRef] [PubMed]

68. Jones, C.D.; Simmons, H.T.D.; Horner, K.E.; Liu, K.; Thompson, R.L.; Steed, J.W. Braiding, branching and chiral amplification of nanofibres in supramolecular gels. Nat. Chem. 2019, 11, 375-381. [CrossRef] [PubMed]

69. Jones, C.D.; Kennedy, S.R.; Walker, M.; Yufit, D.S.; Steed, J.W. Scrolling of Supramolecular Lamellae in the Hierarchical SelfAssembly of Fibrous Gels. Chem 2017, 3, 603-628. [CrossRef]

70. Baker, M.B.; Albertazzi, L.; Voets, I.K.; Leenders, C.M.; Palmans, A.R.; Pavan, G.M.; Meijer, E.W. Consequences of chirality on the dynamics of a water-soluble supramolecular polymer. Nat. Commun. 2015, 6, 6234. [CrossRef] [PubMed]

71. Knani, D.; Alperstein, D. Simulation of DBS, DBS-COOH, and DBS-CONHNH2 as Hydrogelators. J. Phys. Chem. A 2017, 121, 1113-1120. [CrossRef] [PubMed]

72. Angelerou, M.G.F.; Frederix, P.W.J.M.; Wallace, M.; Yang, B.; Rodger, A.; Adams, D.J.; Marlow, M.; Zelzer, M. Supramolecular Nucleoside-Based Gel: Molecular Dynamics Simulation and Characterization of Its Nanoarchitecture and Self-Assembly Mechanism. Langmuir 2018, 34, 6912-6921. [CrossRef] [PubMed] 
73. Draper, E.R.; Dietrich, B.; McAulay, K.; Brasnett, C.; Abdizadeh, H.; Patmanidis, I.; Marrink, S.J.; Su, H.; Cui, H.; Schweins, R.; et al. Using Small-Angle Scattering and Contrast Matching to Understand Molecular Packing in Low Molecular Weight Gels. Matter 2020, 2, 764-778. [CrossRef]

74. Dunfield, L.G.; Burgess, A.W.; Scheraga, H.A. Energy parameters in polypeptides. 8. Empirical potential energy algorithm for the conformational analysis of large molecules. J. Phys. Chem. 1978, 82, 2609-2616. [CrossRef]

75. Yang, L.; Tan, C.-H.; Hsieh, M.-J.; Wang, J.; Duan, Y.; Cieplak, P.; Caldwell, J.; Kollman, P.A.; Luo, R. New-Generation Amber United-Atom Force Field. J. Phys. Chem. B 2006, 110, 13166-13176. [CrossRef] [PubMed]

76. Chen, B.; Potoff, J.J.; Siepmann, J.I. Monte Carlo Calculations for Alcohols and Their Mixtures with Alkanes. Transferable Potentials for Phase Equilibria. 5. United-Atom Description of Primary, Secondary, and Tertiary Alcohols. J. Phys. Chem. B 2001, 105, 3093-3104. [CrossRef]

77. Martin, M.G.; Siepmann, J.I. Transferable Potentials for Phase Equilibria. 1. United-Atom Description ofn-Alkanes. J. Phys. Chem. B 1998, 102, 2569-2577. [CrossRef]

78. Stubbs, J.M.; Potoff, J.J.; Siepmann, J.I. Transferable Potentials for Phase Equilibria. 6. United-Atom Description for Ethers, Glycols, Ketones, and Aldehydes. J. Phys. Chem. B 2004, 108, 17596-17605. [CrossRef]

79. Tjörnhammar, R.; Edholm, O. Reparameterized United Atom Model for Molecular Dynamics Simulations of Gel and Fluid Phosphatidylcholine Bilayers. J. Chem. Theory Comput. 2014, 10, 5706-5715. [CrossRef] [PubMed]

80. Gordon, R.; Stober, S.T.; Abrams, C.F. Effects of Optical Purity and Finite System Size on Self-Assembly of 12-Hydroxystearic Acid in Hexane: Molecular Dynamics Simulations. J. Phys. Chem. B 2017, 121, 9223-9233. [CrossRef] [PubMed]

81. Huda, M.M.; Rai, N. Probing Early-Stage Aggregation of Low Molecular Weight Gelator in an Organic Solvent. J. Phys. Chem. B 2020, 124, 2277-2288. [CrossRef]

82. Kmiecik, S.; Gront, D.; Kolinski, M.; Wieteska, L.; Badaczewska-Dawid, A.E.; Kolinski, A. Coarse-Grained Protein Models and Their Applications. Chem. Rev. 2016, 116, 7898-7936. [CrossRef]

83. Noid, W.G. Perspective: Coarse-grained models for biomolecular systems. J. Chem. Phys. 2013, 139, 090901. [CrossRef] [PubMed]

84. Marrink, S.J.; Risselada, H.J.; Yefimov, S.; Tieleman, D.P.; De Vries, A.H. The Martini Force Field: Coarse Grained Model for Biomolecular Simulations. J. Phys. Chem. B 2007, 111, 7812-7824. [CrossRef] [PubMed]

85. de Jong, D.H.; Singh, G.; Bennett, W.D.; Arnarez, C.; Wassenaar, T.A.; Schäfer, L.V.; Periole, X.; Tieleman, D.P.; Marrink, S.J. Improved Parameters for the Martini Coarse-Grained Protein Force Field. J. Chem. Theory Comput. 2013, 9, 687-697. [CrossRef]

86. Lee, O.-S.; Cho, V.; Schatz, G.C. Modeling the Self-Assembly of Peptide Amphiphiles into Fibers Using Coarse-Grained Molecular Dynamics. Nano Lett. 2012, 12, 4907-4913. [CrossRef]

87. Basavalingappa, V.; Guterman, T.; Tang, Y.; Nir, S.; Lei, J.; Chakraborty, P.; Schnaider, L.; Reches, M.; Wei, G.; Gazit, E. Expanding the Functional Scope of the Fmoc-Diphenylalanine Hydrogelator by Introducing a Rigidifying and Chemically Active Urea Backbone Modification. Adv. Sci. 2019, 6, 1900218. [CrossRef]

88. Nguyen, H.D.; Hall, C.K. Molecular dynamics simulations of spontaneous fibril formation by random-coil peptides. Proc. Natl. Acad. Sci. USA 2004, 101, 16180-16185. [CrossRef] [PubMed]

89. Fu, I.W.; Markegard, C.B.; Chu, B.K.; Nguyen, H.D. The Role of Electrostatics and Temperature on Morphological Transitions of Hydrogel Nanostructures Self-Assembled by Peptide Amphiphiles Via Molecular Dynamics Simulations. Adv. Healthc. Mater. 2013, 2, 1388-1400. [CrossRef]

90. Xiong, Q.; Jiang, Y.; Cai, X.; Yang, F.; Li, Z.; Han, W. Conformation Dependence of Diphenylalanine Self-Assembly Structures and Dynamics: Insights from Hybrid-Resolution Simulations. ACS Nano 2019, 13, 4455-4468. [CrossRef]

91. Badaczewska-Dawid, A.E.; Kolinski, A.; Kmiecik, S. Computational reconstruction of atomistic protein structures from coarsegrained models. Comput. Struct. Biotechnol. J. 2020, 18, 162-176. [CrossRef]

92. Otero-De-La-Roza, A.; Johnson, E.R.; Contreras-Garcia, J. Revealing non-covalent interactions in solids: NCI plots revisited. Phys. Chem. Chem. Phys. 2012, 14, 12165-12172. [CrossRef]

93. Johnson, E.R.; Keinan, S.; Mori-Sánchez, P.; Contreras-Garcia, J.; Cohen, A.J.; Yang, W. Revealing Noncovalent Interactions. J. Am. Chem. Soc. 2010, 132, 6498-6506. [CrossRef]

94. Boto, R.Á.; Peccati, F.; Laplaza, R.; Quan, C.; Carbone, A.; Piquemal, J.-P.; Maday, Y.; Contreras-García, J. NCIPLOT4: Fast, Robust, and Quantitative Analysis of Noncovalent Interactions. J. Chem. Theory Comput. 2020, 16, 4150-4158. [CrossRef] [PubMed]

95. Lefebvre, C.; Rubez, G.; Khartabil, H.; Boisson, J.C.; Contreras-García, J.; Hénon, E. Accurately Extracting the Signature of Intermolecular Interactions Present in the NCI plot of the Reduced Density Gradient versus Electron Density. Phys. Chem. Chem. Phys. 2017, 19, 17928-17936. [CrossRef]

96. Laplaza, R.; Peccati, F.; Boto, R.A.; Quan, C.; Carbone, A.; Piquemal, J.P.; Maday, Y.; Contreras-García, J. NCIPLOT and the Analysis of Noncovalent Interactions using the Reduced Density Gradient. Wiley Interdiscip. Rev. Comput. Mol. Sci. 2021, 11, e1497. [CrossRef]

97. Li, Z.H.; Yang, H.L.; Adam, K.M.; Yao, H.; Wei, T.B.; Zhang, Y.M.; Lin, Q. Theoretical and Experimental Insights into the Self-Assembly and Ion Response Mechanisms of Tripodal Quinolinamido-Based Supramolecular Organogels. ChemPlusChem 2021, 86, 146-154. [CrossRef]

98. Bettens, T.; Lacanau, V.; Van Lommel, R.; De Maeseneer, T.; Vandeplassche, W.; Bertouille, J.; Brancart, J.; Barlow, T.M.A.; Woller, T.; Van den Brande, N.; et al. Towards the Understanding of Halogenation in Peptide Hydrogels: A Quantum Chemical Approach. Mater. Adv. 2021. [CrossRef] 
99. Contreras-García, J.; Boto, R.A.; Izquierdo-Ruiz, F.; Reva, I.; Woller, T.; Alonso, M. A Benchmark for the Non-Covalent Interaction (NCI) index or ... is it Really all in the Geometry? Theor. Chem. Acc. 2016, 135, 242-254. [CrossRef]

100. Pedre, B.; Van Bergen, L.A.H.; Palló, A.; Rosado, L.A.; Dufe, V.T.; Van Molle, I.; Wahni, K.; Erdogan, H.; Alonso, M.; De Proft, F.; et al. The active site architecture in peroxiredoxins: A case study on Mycobacterium tuberculosis AhpE. Chem. Commun. 2016, 52, 10293-10296. [CrossRef]

101. Van Bergen, L.A.H.; Alonso, M.; Palló, A.; Nilsson, L.; De Proft, F.; Messens, J. Revisiting sulfur H-bonds in proteins: The example of peroxiredoxin AhpE. Sci. Rep. 2016, 6, 30369. [CrossRef] [PubMed]

102. Kumar, D.K.; Steed, J.W. Supramolecular gel phase crystallization: Orthogonal self-assembly under non-equilibrium conditions. Chem. Soc. Rev. 2014, 43, 2080-2088. [CrossRef] [PubMed]

103. Andrews, J.L.; Pearson, E.; Yufit, D.S.; Steed, J.W.; Edkins, K. Supramolecular Gelation as the First Stage in Ostwald's Rule. Cryst. Growth Des. 2018, 18, 7690-7700. [CrossRef]

104. Ghosh, D.; Lebedyte, I.; Yufit, D.S.; Damodaran, K.K.; Steed, J.W. Selective Gelation of N-(4-pyridyl)nicotinamide by Copper(ii) Salts. CrystEngComm 2015, 17, 8130-8138. [CrossRef]

105. Rodríguez-Llansola, F.; Hermida-Merino, D.; Nieto-Ortega, B.; Ramírez, F.J.; Navarrete, J.T.L.; Casado, J.; Hamley, I.W.; Escuder, B.; Hayes, W.; Miravet, J.F. Self-Assembly Studies of a Chiral Bisurea-Based Superhydrogelator. Chem. A Eur. J. 2012, 18, 14725-14731. [CrossRef]

106. Woodley, S.M.; Catlow, R. Crystal Structure Prediction from First Principles. Nat. Mater. 2008, 7, 937-946. [CrossRef] [PubMed]

107. Nyman, J.; Reutzel-Edens, S.M. Crystal structure prediction is changing from basic science to applied technology. Faraday Discuss. 2018, 211, 459-476. [CrossRef]

108. Ryan, K.; Lengyel, J.; Shatruk, M. Crystal Structure Prediction via Deep Learning. J. Am. Chem. Soc. 2018, 140, 10158-10168. [CrossRef]

109. Maddox, J. Crystals from first principles. Nature 1988, 335, 201. [CrossRef]

110. Price, S.L. Predicting crystal structures of organic compounds. Chem. Soc. Rev. 2013, 43, 2098-2111. [CrossRef] [PubMed]

111. Anderson, K.M.; Day, G.M.; Paterson, M.J.; Byrne, P.; Clarke, N.; Steed, K. Structure Calculation of an Elastic Hydrogel from Sonication of Rigid Small Molecule Components. Angew. Chem. Int. Ed. 2008, 47, 1058-1062. [CrossRef]

112. Adams, D.J.; Morris, K.; Chen, L.; Serpell, L.C.; Bacsa, J.; Day, G.M. The delicate balance between gelation and crystallisation: Structural and computational investigations. Soft Matter 2010, 6, 4144-4156. [CrossRef]

113. Khavasi, H.R.; Esmaeili, M. Is Gelation Behavior Predictable through a Crystal Engineering Approach? A Case Study in Four Similar Coordination Compounds. Langmuir 2019, 35, 4660-4671. [CrossRef]

114. Adalder, T.K.; Dastidar, P. Crystal Engineering Approach toward Selective Formation of an Asymmetric Supramolecular Synthon in Primary Ammonium Monocarboxylate (PAM) Salts and Their Gelation Studies. Cryst. Growth Des. 2014, 14, $2254-2262$. [CrossRef]

115. Zurcher, D.M.; McNeil, A.J. Tools for Identifying Gelator Scaffolds and Solvents. J. Org. Chem. 2015, 80, 2473-2478. [CrossRef]

116. Veits, G.K.; Carter, K.K.; Cox, S.J.; McNeil, A.J. Developing a Gel-Based Sensor Using Crystal Morphology Prediction. J. Am. Chem. Soc. 2016, 138, 12228-12233. [CrossRef]

117. BIOVA Materials Studio. Dassault Systèmes; Dassault Systèmes: San Diego, CA, USA, 2021.

118. Hisaki, I.; Kometani, E.; Tohnai, N.; Miyata, M. Gelation or crystallization? Subtle balance of structural factors for assembly of DBA derivatives with methyl esters. CrystEngComm 2015, 17, 8079-8084. [CrossRef]

119. Houton, K.A.; Morris, K.L.; Chen, L.; Schmidtmann, M.; Jones, J.T.A.; Serpell, L.C.; Lloyd, G.O.; Adams, D.J. On Crystal versus Fiber Formation in Dipeptide Hydrogelator Systems. Langmuir 2012, 28, 9797-9806. [CrossRef] [PubMed]

120. Barker, E.C.; Martin, A.D.; Garvey, C.J.; Goh, C.Y.; Jones, F.; Mocerino, M.; Skelton, B.W.; Ogden, M.I.; Becker, T. Thermal annealing behaviour and gel to crystal transition of a low molecular weight hydrogelator. Soft Matter 2017, 13, 1006-1011. [CrossRef] [PubMed]

121. Hirst, A.R.; Smith, D.K. Solvent Effects on Supramolecular Gel-Phase Materials: Two-Component Dendritic Gel. Langmuir 2004, 20, 10851-10857. [CrossRef]

122. Partridge, K.S.; Smith, D.K.; Dykes, G.M.; McGrail, P.T. Supramolecular dendritic two-component gel. Chem. Commun. 2001, 4, 319-320. [CrossRef]

123. Niu, L.; Song, J.; Li, J.; Tao, N.; Lu, M.; Fan, K. Solvent effects on the gelation performance of melamine and 2-ethylhexylphosphoric acid mono-2-ethylhexyl ester in water-organic mixtures. Soft Matter 2013, 9, 7780-7786. [CrossRef]

124. Zhu, G.; Dordick, J.S. Solvent Effect on Organogel Formation by Low Molecular Weight Molecules. Chem. Mater. 2006, 18, 5988-5995. [CrossRef]

125. Lin, P.; Zhang, N.-X.; Li, J.-J.; Zhang, J.; Liu, J.-H.; Zhang, B.; Song, J. To gel or not to gel: A prior prediction of gelation in solvent mixtures. Chin. Chem. Lett. 2017, 28, 771-776. [CrossRef]

126. Lan, Y.; Corradini, M.G.; Weiss, R.G.; Raghavan, S.R.; Rogers, M.A. To gel or not to gel: Correlating molecular gelation with solvent parameters. Chem. Soc. Rev. 2015, 44, 6035-6058. [CrossRef] [PubMed]

127. Bhardwaj, V.; Ballabh, A. Design, synthesis, and application of a new series of organogelator using crystal engineering approach and solvent parameter study: A synergetic approach. J. Mol. Liq. 2021, 322, 114520. [CrossRef]

128. Iqbal, S.; Khan, A.A. Supramolecular self-assembly and physical-gel formation in disc-like liquid crystals: A scalable predictive model for gelation and an application in photovoltaics. RSC Adv. 2019, 9, 6335-6345. [CrossRef] 
129. Diehn, K.K.; Oh, H.; Hashemipour, R.; Weiss, R.G.; Raghavan, S.R. Insights into organogelation and its kinetics from Hansen solubility parameters. Toward a priori predictions of molecular gelation. Soft Matter 2014, 10, 2632. [CrossRef]

130. Yan, N.; Xu, Z.; Diehn, K.K.; Raghavan, S.R.; Fang, Y.; Weiss, R.G. How Do Liquid Mixtures Solubilize Insoluble Gelators? Self-Assembly Properties of Pyrenyl-Linker-Glucono Gelators in Tetrahydrofuran-Water Mixtures. J. Am. Chem. Soc. 2013, 135, 8989-8999. [CrossRef]

131. Delbecq, F.; Adenier, G.; Ogue, Y.; Kawai, T. Gelation properties of various long chain amidoamines: Prediction of solvent gelation via machine learning using Hansen solubility parameters. J. Mol. Liq. 2020, 303, 112587. [CrossRef]

132. Hansen, C.M. 50 Years with Solubility Parameters-Past and Future. Prog. Org. Coat. 2004, 51, 77-84. [CrossRef]

133. Raynal, M.; Bouteiller, L. Organogel formation rationalized by Hansen solubility parameters. Chem. Commun. 2011, 47, 8271-8273. [CrossRef]

134. Bonnet, J.; Suissa, G.; Raynal, M.; Bouteiller, L. Organogel formation rationalized by Hansen solubility parameters: Dos and don'ts. Soft Matter 2014, 10, 3154-3160. [CrossRef] [PubMed]

135. Bonnet, J.; Suissa, G.; Raynal, M.; Bouteiller, L. Organogel Formation Rationalized by Hansen Solubility Parameters: Influence of Gelator Structure. Soft Matter 2015, 11, 2308-2312. [CrossRef]

136. Nunes, D.R.; Raynal, M.; Isare, B.; Albouy, P.-A.; Bouteiller, L. Organogel formation rationalized by Hansen solubility parameters: Improved methodology. Soft Matter 2018, 14, 4805-4809. [CrossRef] [PubMed]

137. Nunes, D.R.; Reche-Tamayo, M.; Ressouche, E.; Raynal, M.; Isare, B.; Foury-Leylekian, P.; Albouy, P.-A.; Brocorens, P.; Lazzaroni, R.; Bouteiller, L. Organogel Formation Rationalized by Hansen Solubility Parameters: Shift of the Gelation Sphere with the Gelator Structure. Langmuir 2019, 35, 7970-7977. [CrossRef] [PubMed]

138. Singh, A.; Auzanneau, F.-I.; Corradini, M.G.; Grover, G.; Weiss, R.G.; Rogers, M.A. Molecular Nuances Governing the SelfAssembly of 1,3:2,4-Dibenzylidene-d-sorbitol. Langmuir 2017, 33, 10907-10916. [CrossRef] [PubMed]

139. Gao, J.; Wu, S.; Rogers, M.A. Harnessing Hansen solubility parameters to predict organogel formation. J. Mater. Chem. 2012, 22, 12651-12658. [CrossRef]

140. Lan, Y.Q.; Corradini, M.G.; Liu, X.; May, T.E.; Borondics, F.; Weiss, R.G.; Rogers, M.A. Comparing and Correlating Solubility Parameters Governing the Self-Assembly of Molecular Gels Using 1,3:2,4-Dibenzylidene Sorbitol as the Gelator. Langmuir 2014, 30, 14128-14142. [CrossRef]

141. Lan, Y.; Corradini, M.G.; Rogers, M.A. Do Molecular Gelators Cluster in Hansen Space? Cryst. Growth Des. 2014, 14, 4811-4818. [CrossRef]

142. Lan, Y.; Lv, M.; Guo, S.; Nasr, P.; Ladizhansky, V.; Vaz, R.F.; Corradini, M.G.; Hou, T.; Ghazani, S.M.; Marnangoni, A.; et al. Molecular motifs encoding self-assembly of peptide fibers into molecular gels. Soft Matter 2019, 15, 9205-9214. [CrossRef]

143. Moreira, I.P.; Scott, G.G.; Ulijn, R.V.; Tuttle, T. Computational prediction of tripeptide-dipeptide co-assembly. Mol. Phys. 2018, 117, 1151-1163. [CrossRef]

144. Frederix, P.; Ulijn, R.V.; Hunt, N.T.; Tuttle, T. Virtual Screening for Dipeptide Aggregation: Toward Predictive Tools for Peptide Self-Assembly. J. Phys. Chem. Lett. 2011, 2, 2380-2384. [CrossRef] [PubMed]

145. Frederix, P.; Scott, G.G.; Abul-Haija, Y.M.; Kalafatovic, D.; Pappas, C.G.; Javid, N.; Hunt, N.T.; Ulijn, R.V.; Tuttle, T. Exploring the sequence space for (tri-)peptide self-assembly to design and discover new hydrogels. Nat. Chem. 2015, 7, 30-37. [CrossRef] [PubMed]

146. Gupta, J.K.; Adams, D.J.; Berry, N.G. Will it gel? Successful computational prediction of peptide gelators using physicochemical properties and molecular fingerprints. Chem. Sci. 2016, 7, 4713-4719. [CrossRef] [PubMed]

147. Li, F.; Han, J.; Cao, T.; Lam, W.; Fan, B.; Tang, W.; Chen, S.; Fok, E.; Li, L. Design of self-assembly dipeptide hydrogels and machine learning via their chemical features. Proc. Natl. Acad. Sci. USA 2019, 116, 11259-11264. [CrossRef]

148. Van Lommel, R.; Zhao, J.; De Borggraeve, W.M.; De Proft, F.; Alonso, M. Molecular dynamics based descriptors for predicting supramolecular gelation. Chem. Sci. 2020, 11, 4226-4238. [CrossRef]

149. Grimme, S.; Schreiner, P.R. Computational Chemistry: The Fate of Current Methods and Future Challenges. Angew. Chem. Int. Ed. 2018, 57, 4170-4176. [CrossRef] [PubMed]

150. Butler, K.T.; Davies, D.W.; Cartwright, H.; Isayev, O.; Walsh, A. Machine learning for molecular and materials science. Nature 2018, 559, 547-555. [CrossRef] [PubMed]

151. Liu, Y.; Zhao, T.; Ju, W.; Shi, S. Materials discovery and design using machine learning. J. Mater. 2017, 3, 159-177. [CrossRef]

152. Schmidt, J.; Marques, M.R.; Botti, S.; Marques, M.A. Recent Advances and Applications of Machine Learning in Solid-State Materials Science. NPJ Comput. Mater. 2019, 5, 83. [CrossRef]

153. Sanchez-Lengeling, B.; Aspuru-Guzik, A. Inverse molecular design using machine learning: Generative models for matter engineering. Science 2018, 361,360-365. [CrossRef]

154. van Teijlingen, A.; Tuttle, T. Beyond Tripeptides Two-Step Active Machine Learning for Very Large Data sets. J. Chem. Theory Comput. 2021, 17, 3221-3232. [CrossRef] [PubMed]

155. Zanganeh, S.; Firoozpour, L.; Sardari, S.; Afgar, A.; Cohan, R.A.; Mohajel, N. Novel Descriptors Derived from the Aggregation Propensity of Di- and Tripeptides Can Predict the Critical Aggregation Concentration of Longer Peptides. ACS Omega 2021, 6, 13331-13340. [CrossRef] [PubMed] 